\title{
Correspondence
}

\section{Child health services after reorganisation}

Sir,

I was pleased to see the article on this important issue. Unfortunately the facts are more unsatisfactory and uncertain than Dr Wilson's analysis suggested. ${ }^{1}$

The question is not what is best for paediatricians or clinical medical officers, but what is best for children and their parents? Children have special needs which they cannot articulate for themselves; therefore society has a duty to ensure that these are identified and consistently represented.

Whose voices are speaking for children at the beginning of reorganisation? At government level the Children's Committee was silenced by the present government before it had found its voice. In the regions the previous Paediatric Advisory Committee may be retained. If it is, it will be concerned with regional planning and major facilities; committed to the slow uphill struggle to bring the scattered children in hospital into a comprehensive children's department or hospital. In the district there is no effective voice within the system. The significance of the Area SCM (CH) lay in her ability to speak for children to the Area Medical Officer and to have rightful access to the arta team of officers. However, her experience of child health was generally limited to the developmental and preventive aspects. This was certainly valuable in the 'child indifferent' climate which has prevailed throughout my professional life; it was not the optimum solution, and the generic community physician will be a weaker advocate. Children are not an addendum to society; they are its responsibility and its future.

As I see it (and I shall be pleased to be corrected) there is no established body at district level within the service to keep children's needs under constant review, and able to speak with authority to the district team of officers. Such a body must be established; its form should be decided by those providing the clinical and preventive care of children in the district. In recent years the Joint Care Planning Team, provided its composition was sufficiently representative, was one possible pattern. It was not mandatory, and its advice was not always heeded. A cogwheel type of committee which stretched into the community, representing both primary and secondary care, existed in most districts and was effective if its authority was recognised.

The previous government was committed to an integrated health service for children as is the present one; surely it would be politic for all the professional organisations to work together for its realisation. Senior and experienced clinical medical officers could assist this process by joining their own association or by seeking associate membership of the British Paediatric Association.
The Forfar committee's far reaching report contains a gracious and generous way to achieve the integration of clinical medical officers into general practice as an essential part of primary care. I understand another committee is considering how the senior clinical medical officers can evolve into consultant paediatricians with developmental, educational, and social responsibilities.

The voice for children is only a whisper and its restoration will depend on the British Paediatric Association acting in unison with the representatives of the clinical medical officers and the Royal College of General Practitioners. Together they could succeed; divided they will certainly fail.

\section{Reference}

1 Wilson J. Child health services after reorganisation. Arch Dis Child 1982; 57: 1-2.

DONALD CourT

8 Towers Avenue, Newcastle upon Tyne NE2 $3 Q E$

\section{Glucose-polymer in acute diarrhoea}

Sir,

Sandhu et al. ${ }^{1}$ gave a glucose polymer to 7 babies with mild diarrhoea. One refused it, 4 did well, one had diarrhoea for 5 days until it was stopped, and one became very ill. These outcomes may correspond to the possible fates of the Caloreen. It may be rejected by the old and discriminating, and with it the water he needs. It may be hydrolysed slowly and absorbed promptly by the not too ill, as the authors hoped. It may be passed unchanged or as an oligosaccharide, taking water with it and perpetuating a glucose-negative diarrhoea. Lastly it may be hydrolysed completely, or nearly so, but not absorbed. In this form it will draw from the body up to $1 \frac{1}{2}$ times its volume of water (but not salt) causing hypovolaemia, perhaps hypernatraemia, and a very sick baby. If he is later given dilute liquid by mouth 'water ad libitum' or vein, he risks cerebral and renal oedema and fits, or anuria.

It seems unwise on the present evidence to recommend Caloreen for babies with diarrhoea.

\section{Reference}

1 Sandhu B K, Jones B J M, Brook C G D, Silk D B A. Oral rehydration in acute infantile diarrhoea with a glucose-polymer electrolyte solution. Arch Dis Child $1982 ; 57: 152-4$.

T H HuGHES-DAVIES Ealing Hospital, Southall, Middlesex 